\title{
Consideraciones en torno al código de ética de la prensa de El Salvador
}

\section{Anotaciones previas}

Hoy día se ha vuelto lugar común sostener que nuestra sociedad se encamina hacia una verdadera crisis de valores. Algunas conductas que constatan esta crisis son el desacato a las leyes, la negación de los derechos fundamentales de las personas; el vacio de autoridad y de liderazgo moral, la impunidad frente al irrespeto de los valores, el conflicto de intereses en la aplicación de principios éticos que suele resolverse con la "doble moral", las incoherencias en las autoridades responsables. de la transmisión de valores, la falta de equilibrio entre derechos y responsabilidades, y el predominio de intereses individuales o sectoriales sobre el bien de la sociedad considerada como un todo (ver Temas claves, 1999). Es, por consiguiente, una crisis estructural que afecta a las instituciones y a las personas de forma permanente. Los medios de comunicación en general, y el periodismo en particular, no han escapado de este vacío ético.

$\mathrm{Si}$ bien las tres funciones que parecen caracterizar al periodismo (informar, formar opinión y tematizar la realidad), se han constituido en uno de los modos principales que tiene la población para conocer la realidad y tomar posición ante ella, no menos cierto es que esas funciones pueden desvirtuarse en manipulación informativa, comunicación sesgada y en opinión interesada, en razón del mismo carácter de tales medios; es decir, de su inevitable vinculación a lo empresarial, a lo político, a lo ideológico e inclusive a lo religioso. En este contexto, la moral de la información posibilita un distanciamiento crítico respecto al ejercicio de este derecho.

Los criterios éticos que deben orientar el hecho humano de la información pueden ser resumidos en tres grupos: (a) derecho a la información, que se fundamenta tanto en la dignidad de la persona como en la exigencia del bien común, lo cual pasa por garantizar el acceso de los medios a las fuentes de información y el acceso de los ciudadanos y ciudadanas a los medios para informar e informarse; $(b)$ exigencias objetivas de la información, que consiste en reproducir, como objeto teórico informativo, el hecho noticioso con toda su complejidad, logrando superar el artificio de identificar información con opinión, difusión con propaganda, lo nacional con lo partidista; (c) el montaje estructural del proceso informativo, cuyos momentos principales son: acceso a las fuentes por parte de los informadores, libre circulación de las noticias y receptividad activà por parte del público (ver Vidal, 1980).

Con estos criterios o marco de valores referenciales, que conllevan, por un lado, la forma ética de ejercer el derecho a la información y, por otra parte, nos previene de las posibles degradaciones que pueden producirse en la práctica, vamos a comentar los contenidos del Código de ética de la prensa de El Salvador. Tres son los puntos que contiene nuestro análisis: primero, abordaremos los problemas éticos del trabajo periodístico en nuestro país; segundo, describiremos los contenidos básicos del Código y, tercero, emitiremos un juicio sobre los alcances y limitaciones del mismo.

\section{Problemas éticos del trabajo periodístico}

La necesidad de un código de ética no surge de preocupaciones abstractas o moralistas. Surge, eso sí, a partir de los problemas concretos con los que tiene que habérselas el periodista en su trabajo 
diario. De igual modo, la ética periodística, en cuanto reflexión sobre los auténticos bienes que se le ofrecen al ser humano en este campo, buscará fundamentar, a partir de las circunstancias dadas, cuál es la posibilidad concreta preferible en el ámbito de la información.

Los problemas del periodismo nacional no son muy distintos a los problemas del periodismo en América Latina. Para algunos autores (ver Virtue, 1998), el comportamiento antiético de los informadores se puede dividir en tres categorías. La primera categoría está relacionada con los intereses gerenciales de los medios de comunicación, que no siempre favorecen una labor informativa independiente. Las notas se eliminan o seleccionan, se destacan o disimulan para satisfacer a determinados anunciantes, gobemantes, políticos, empresarios o a los intereses del dueño o del director de ese medio. Con frecuencia se escuchan quejas de periodistas a los que se les censuran sus notas porque no se acomodan a la ideología de los dueños del medio, o porque en alguna forma afectan los intereses publicitarios. En muchas ocasiones, esta censura se hace en nombre de razones técnicas o de políticas informativas, cuando la realidad es que están motivadas por un conflicto de intereses.

Cuando se niega la pluralidad informativa eliminando la información de los actores sociales considerados adversarios, cuando la información es parcial y tendenciosa, entonces la libertad de prensa, implícita en el derecho a la información, sólo sirve para asegurar los intereses de unos pocos y deja de ser efectivo para los demás. Deja de ser libertad de las ideologizaciones para subordinarse a ellas. En consecuencia, se falta gravemente a la ética de la información. Esta práctica es todavía muy común en la prensa salvadoreña y suele aparecer con especial énfasis en las coyunturas electorales, al priorizar notas o reportajes de algún personaje o partido político afín, con el propósito de fomentar una imagen positiva o desprestigiar a aquellos protagonistas con los que se está en desacuerdo.

Esto último ha sido nuevamente puesto de manifiesto en un análisis sobre el papel protagónico que tomó uno de los principales periódicos del país en contra del funcionamiento de los casinos (ver Proceso, 874 y 875). El cotejo muestra que el interés y preocupación del rotativo por dicho tema -juzgado con un reacio conservadurismo moral- ocultaba mucha política partidista. En efecto, el periódico - a través de suplementos especiales, editoriales y noticias- pretendió hacer creer que el actual alcalde y candidato para un segundo período por los partidos de oposición, es el responsable de la existencia de los casinos en el país (argumento muy discutible). "Repetir insistentemente que él los autorizó, al tiempo que se notifica la dudosa procedencia de los propietarios, no puede más que querer enviar el mensaje de que el alcalde respalda criminales" (Proceso, 874). Curiosamente, este tipo de señalamientos coincide con el discurso del candidato oficial quien ha emprendido una campaña (fuera del período estipulado) contra el edil, tomando como bandera el desacuerdo con las salas de juego.

La segunda categoría del comportamiento antiético es la corrupción en la sala de redacción expresada en las prebendas y en el conflicto de intereses. $Y$ es que, en un país donde la mayoría de ciudadanos no cree ni confía en la clase política ni en las instituciones partidarias; donde algunos sectores vinculados al poder político o empresarial pagan a los periodistas para que publique propaganda disfrazada de información; donde un buen número de periodistas tiene que sobrevivir con un salario que no resuelve sus necesidades básicas; ocurre que las prebendas o regalos directos o indirectos se convierten en una práctica más o menos común que atenta contra la ética periodística. Hay quienes llegan a considerar que las prebendas constituyen una parte "normal" de sus ingresos. Claro está, que los que ofrecen estos beneficios pasarán tarde o temprano la factura.

Por otra parte, los conflictos de interés -reales o aparentes - pueden surgir cuando el periodista asume responsabilidades paralelas (asesorías, encargado de comunicaciones, relacionista público, etc.) a su labor informativa; cuando su afiliación política interfiere o entorpece la cobertura de una fuente; cuando aprovecha en beneficio propio o sectorial su posición de informador. Si esto es así, se corre el peligro de afectar la objetividad que demanda la ética de la información. El caso ocurrido en El Salvador con algunos periodistas deportivos, que recibían dinero en concepto de servicios profesionales a cambio de proyectar una imagen positiva de un deporte en crisis, es sólo un ejemplo que se repite en otros ámbitos de la vida nacional. 
Otro aspecto relacionado con los conflictos de interés "es la tentación de convertirse en allegado o íntimo de los poderosos. Es la tentación del caché y el prestigio que da el identificarse con las fuentes. Hay periodistas que cultivan las relaciones 'por lo alto' y que de pronto sin darse cuenta terminan siendo utilizados y manipulados. ¿No será preferible que el periodista sea más bien una especie de 'solitario' y de pronto hasta 'impopular' ante los funcionarios y poderosos?" (Forero y González, 1990).

La tercera categoría se refiere al comportamiento antiético en la investigación, preparación y redacción de

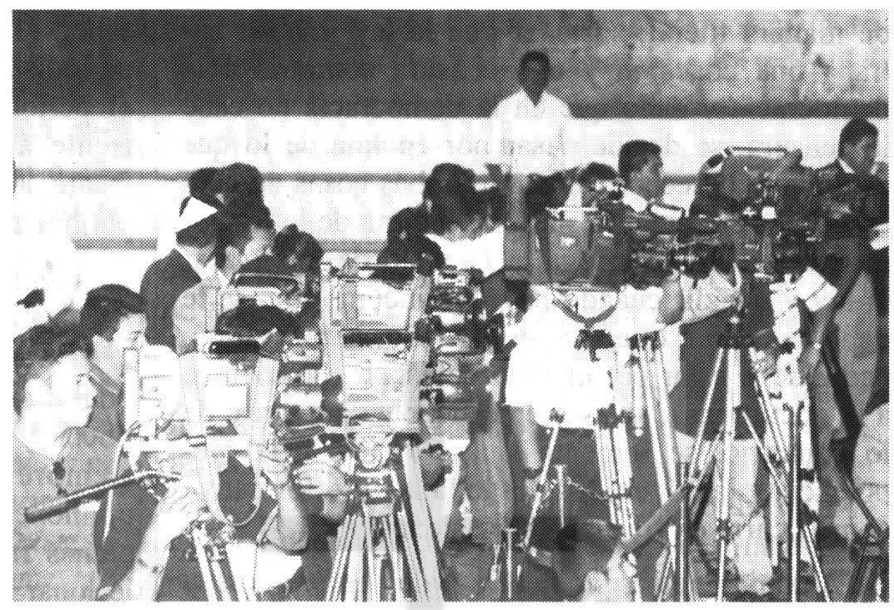

la noticia. Las tres quejas recurrentes del público en muchos países son que, con frecuencia, las noticias contienen errores (sin que haya rectificación), que los mędios tienden al sensacionalismo (en abandono de la verdad), y que la prensa invade la privacidad llegando hasta la impunidad y la prepotencia.

Aun cuando se reconoce que toda actividad periodistica debe ser investigativa, la agenda de noticias sigue dominada por fuentes oficiosas en menoscabo de la investigación que pueda dar cuenta de los acontecimientos más importantes de la realidad. Se sigue poniendo énfasis en la coyuntura y no en los problemas estructurales, se da mayor protagonismo a las personalidades y funcionarios (aunque éstos sean de pocas luces) y se reduce la opinión del ciudadano común.

Por lo que toca al tratamiento de la noticia, los que alguna vez hemos sido entrevistados, sobre todo por la prensa escrita, constatamos faltas como apropiación de las ideas del entrevistado que el periodista presenta como suyas, distorsión o manipulación de contenidos (se le atribuyen cosas que no dijo o se ignoran otras que sí dijo) y, en el peor de los casos, se concede una entrevista en la que pueden invertirse varios minutos u horas $y$, al final, es totalmente desechada o trivializada.

Asimismo, el papel cada vez más determinante de la economía publicitaria sobre las políticas informativas, conlleva el peligro de que la estrategia del markenting termine decidiendo qué y cómo informar. Esto puede derivar en graves faltas éticas: banalización de la realidad (lo noticiable es lo vendible), orientación hacia un periodismo sen-

sacionalista (distorsión de los hechos mediante la acentuación de aspectos emocionales), pérdida del contexto de la noticia (predominio de lo impactante sobre lo importante).

En otro orden, a veces se toma demasiado en serio aquello de que la prensa es el cuarto poder. $Y$, en nombre de una irrestricta libertad de información, se cae en la impunidad informativa que deriva en encubrimiento, desinformación y daño al honor, al respeto y a la dignidad de las personas. Pero no sólo eso, en nombre de esa libertad, la prensa se atreve a incursionar en campos que no son de su competencia. Por ejemplo, decidir cuando se debe hacer una interpretación "inteligente" de la ley. Ese fue el caso en la disputa que se abrió en nuestro país en tomo a la violación de la Ley del Menor Infractor, al dar a conocer la identidad del joven convicto de varios asesinatos (dado a conocer por los medios como "el directo") que se fugó del presidio y posteriormente fue recapturado. La gran prensa, sobre todo, justificó su acción alegando que actuó movida por el interés general: la fuga del enemigo número uno ponía en peligro grave e inmediato a la ciudadanía.

Dejando de lado el argumento, muy discutible por cierto, de que un joven de diecisiete años pudiera poner en peligro a toda la ciudadanía y sea él el principal enemigo público; la justificación de la violación de la ley dada por estos "defensores" de la libertad de prensa no sólo es antiética, sino también contraria al espíritu del estado de derecho. Sostener que la delincuencia juvenil ha puesto al país en emergencia crítica (otro argumento discutible) y, que, por tanto, la ley es obsoleta y puede ser interpretada con inteligencia y no 
de manera literal; sostener que la ley minoril entraña una coacción y una censura contraria a la democracia y dado que en la democracia no cabe la censura, se decide pasar por encima de lo que estipula el derecho. Defender ambas cosas no sólo es falaz sino querer estar por encima de la ley. Si la gran prensa se arroga la facultad de interpretar la ley y decidir cuándo hay que incumplirla, se le debe recordar que, en un Estado democrático, nadie debe estar por encima de ésta y eso incluye a la gran prensa, a sus propietarios y directores; de lo contrario, se fomenta la arbitrariedad, la prepotencia y la impunidad desde la labor informativa como ocurre en frecuentes ocasiones.

A partir de estos problemas reales, entre otros, se plantea la necesidad y el interés por la conformación de un código de ética para periodistas. Esto es muy importante tenerlo en cuenta para evitar valoraciones morales en abstracto, que aluden simplemente a principios generales. Un juicio moral solamente tendrá aplicación en la medida en que parta de los problemas y de las posibilidades reales que tienen los seres humanos en un momento dado de su historia. De ahí que la racionalidad ética supera el "voluntarismo" exacerbante (que sólo se apoya en el furor de las buenas intenciones), el "utopismo" ingenuo (que no parte de lo realmente dado ni de lo realmente posible) y el "posibilismo" paralizante (que bajo el pretexto de que no hay condiciones para el cambio olvida la fuerza del empeño ético).

Frente a estas actitudes, la racionalidad ética insiste en que lo "bueno", en todos los campos de la existencia humana, y el periodismo no es la excepción, hay que buscarlo en las posibilidades concretas que tienen los seres humanos conducentes hacia un mayor y mejor ejercicio de su actividad. En este caso, la actividad relacionada con el derecho a la información. Pero, entre las distintas posibilidades concretas hay que fundamentar de algún modo cuáles son preferibles y en virtud de qué criterios. Este es el propósito de los códigos de ética, sin los cuales se corre el peligro de que los poderes fácticos se apropien de forma exclusiva y excluyente de una actividad que debe ser de suyo social.

\section{Contenidos básicos del Código: alcances y limitaciones}

El Código de ética de la prensa de El Salvador recoge (en sus 39 artículos) un conjunto de normas y criterios que han de orientar seis tipos de relaciones propias de la actividad periodística, a saber: (1) el periodista frente a la sociedad; (2) el periodista frente a las fuentes de información, (3) el periodista frente a la niñez; (4) el periodista frente al funcionario público; (5) el periodista frente a la empresa de comunicación, y (6) el periodista frente a la profesión.

Frente a la sociedad se reconoce que el periodista es un servidor social, por lo que los intereses de la colectividad preceden a cualquier responsabilidad ante las empresas y los poderes públicos y privados (art. 4). Esto implica observar siempre una clara distinción entre hechos $y$ opiniones (art. 5); difundir únicamente informaciones fundamentadas y evitar datos que puedan lesionar o menospreciar la dignidad de las personas o el descrédito injustificado a instituciones públicas o privadas (art. 7); informar de todos los acontecimientos dignos de relieve y evitar la descripción morbosa de la violencia (art. 8 y 9); fomentar el diálogo abierto con los interlocutores y hacer efectivo el derecho de respuesta (art. $10 \mathrm{y}$ 11); defender el derecho de información evitando la discriminación de fuentes (art. 13 y 15); rechazar contratos incompatibles con la integridad y la dignidad de la profesión (art. 14), y promover la figura del Defensor de los lectores, televidentes y radioescuchas (art. 12).

Frente a las fuentes de información se exhorta a la objetividad, la exactitud, el secreto profesional y el respeto a la dignidad de las personas. Esto supone sustentar la información en fuentes fidedignas (art. 16); acceder a las fuentes sin recurrir a procedimientos ilícitos (art. 18); respeto a la confianza que le otorgan las fuentes (artículos 18-21); respeto al derecho de las personas a su propia intimidad (art. 22 y 24), y no prejuzgar, antes del juicio legal, los casos llevados ante un tribunal (art. 23).

Frente a la niñez se pide que el periodista observe y garantice toda legislación internacional reconocida por el Estado salvadoreño, además de las leyes nacionales sobre los derechos del niño y de la niña (art. 26). Esto pasa por: no publicar información que conduzca a identificar a las víctimas de maltrato y hechos de violencia; no publicar los nombres de los padres (art. 27) y por abstenerse de presentar imágenes o nombres de menores en conflicto con la ley (art. 28).

Frente al funcionario público se excita a que el periodista haga prevalecer el derecho a la informa- 
ción por encima de cualquier restricción que pueda vulnerar la transparencia informativa (art. 29). Ello demanda rechazo y denuncia de cualquier tipo de sobomo proveniente de funcionarios públicos o particulares, que pretendan suprimir a alterar información de interés colectivo (art. 30 y 31).

Frente a la empresa de comunicación se espera del periodista lealtad, en cuanto no sea incompatible con su conciencia profesional, con las leyes, la libre expresión y el presente Código de Ética (art. 32). En este marco, el periodista debe potenciar el derecho de respuesta en su dimensión personal y del medio para el que trabaja, así como interesarse para que la empresa periodística proporcione las condiciones adecuadas para su desempeño profesional (art. 33 y 34).

Frente a la profesión se espera que éste (el periodista) la dignifique (art. 35). Lo que supone: no simultanear otras actividades profesionales incompatibles con la ética de la información (art. 36); garantizar el ejercicio de la libre expresión (art. 37), y no "crear" noticias para satisfacer intereses de personas, empresas o instituciones (art. 38).

\subsection{Los alcances}

El Código de Ética de la Asociación de Periodistas de El Salvador (APES) busca unificar periodismo profesional y compromiso ético. Esto, de suyo, es algo muy positivo en cuanto que lo profesional no tiene que ver sólo con la idoneidad y las destrezas manifiestas, sino también con las exigencias del bien común. Es la sociedad como totalidad la que necesita estar bien informada y eso pasa por asegurar una prensa libre, responsable y objetiva.

La esquizofrenia axiológica de la que adolece buena parte del periodismo, sólo es posible superarla cuando se logre unificar profesionalismo y racionalidad ética. En el campo del periodismo, según el Código, esto implica una nueva práctica informativa en la que se reconozca la necesidad de mayor independencia ante las diversas presiones para que en el momento de la investigación, selección, jerarquización y redacción de las noticias, se haga según la trascendencia que tenga para el país y no según lo que favorezca o desfavorezca a la ideología del medio. Significa, además, garantizar el derecho a la información veraz (en su contenido), así como el respeto de los legí- timos derechos y la dignidad de las personas, tanto en la obtención de las noticias como en su difusión.

El "espíritu" del Código es, ciertamente, encomiable:"recuperar la dimensión ética en el quehacer periodístico. Y es que, si la información adquiere hoy día un valor estratégico para el desarrollo económico de los países, para la globalización de los mercados, para la gestión de asuntos públicos y privados, debe serlo también para la humanización de las personas y de la sociedad. Pero ese propósito sólo se logrará cuando se unifique "el saber hacer las cosas" (un hacer periodístico con racionalidad operativa) y "el saber la manera de actuar en la vida" (un hacer periodístico con racionalidad ética), según el bien y el mal del ser humano. La consecuencia de esta unidad será un periodismo "al servicio de la verdad, la justicia, la dignidad humana, el Estado democrático, la cultura de la tolerancia, el perfeccionamiento de la sociedad y la fraternidad de los pueblos" (art. 2).

El enfoque del derecho a la información que contiene el Código es también relevante en virtud de su interpretación democrática. En efecto, por un lado se fundamenta no sólo en la dignidad del individuo, sino a su vez en la exigencia del bien común; y por otra parte, insiste en el carácter inviolable, pero no absoluto de este derecho. Justamente, el Código reconoce que el conjunto de derechos y deberes del periodista deviene del derecho del público a conocer los hechos y las opiniones (art. 3). Por tanto, los sujetos de este derecho no son sólo los periodistas o los propietarios de los medios de comunicación, sino ante todo la sociedad civil, el ciudadano común. Esto es necesario tenerlo presente porque cuando se habla o se debate sobre el derecho a la información, se lo suele identificar con las garantías que tienen o debieran tener los periodistas para ejercer su labor, o con las garantías que demandan los grandes propietarios de los medios de comunicación; independientemente de si hay o no ejercicio real por parte de los ciudadanos para buscar, recibir y difundir información e ideas. En este caso, el derecho de todos se interpreta e identifica con la práctica ejercida por grupos minoritarios.

Ahora bien, este derecho, en cuanto derecho de la sociedad civil, no tiene por qué ser interpretado de forma pasiva (tener derecho a ser informado), sino más bien de forma activa (tener derecho a informar y verter opinión). El Código, en este sentido, plantea que el periodista debe fomentar el diá- 
logo abierto con los lectores, televidentes y radioescuchas (art. 10); debe hacer efectivo el derecho de respuesta en condiciones equivalentes de espacio (art. 11); debe impulsar la figura del Defensor de la colectividad perceptora (Ombudsman de prensa) (art. 12); y debe evitar la exclusión informativa de cualquier fuente que amerite ser tomada en cuenta (art. 13).

En lo que toca al carácter inviolable pero no absoluto de este derecho, el Código reconoce que el ejercicio del derecho a la información tiene sus limitaciones necesarias. Algunos artículos en este sentido, son los siguientes: el periodista debe respetar el derecho de las personas a su propia intimidad (art. 22); deberá guardar el secreto profesional (art. 18); deberá abstenerse de presentar imágenes o nombres de menores en conflicto con la ley (art. 28). Todo ello sin olvidar que el derecho a la intimidad, la privacidad y la honra si bien es inviolable, no tiene un carácter absoluto, es decir, también tiene su límite. Por ejemplo, cuando se trate de asuntos relacionados con la administración pública, el derecho a la información tiene que prevalecer siempre por encima de cualquier restricción que vulnere el principio de la transparencia informativa (art. 29). Aquí el límite está marcado por el interés público (que no ha de confundirse con la curiosidad pública) y por la naturaleza pública de las personas implicadas (en la medida en que una persona desempeña funciones públicas, el círculo de su vida privada se toma cada vez más reducido). Se dan, pues, algunos elementos orientadores para enfrentar el conflicto entre libertad de información y el derecho a la intimidad y el buen nombre. El periodista responsable debe saber discernir para no caer en la tentación del sensacionalismo, evitando noticias de dudoso o ambiguo interés colectivo.

Otro aspecto que merece valorarse es la concepción, explícita en el Código, de los y las periodistas como servidores públicos. Son, por tanto, responsables no sólo frente a los propietarios de los medios de comunicación, sino, sobre todo, frente al gran público. En razón de su responsabilidad social se espera que estén al servicio de la verdad, de la justicia, de la dignidad humana, del estado democrático, etc. (art. 2). Se espera que en su labor tengan prioridad los intereses de la colectividad, antes que los suyos o el de los poderes públicos o privados (art. 4). Servidores sociales con este talante tendrán un gran interés por conocer la verdad de la realidad, por difundirla, por humanizarla; pero especialmente, tendrán la suficiente sensibilidad para dejarse impactar por la realidad de las mayorías pobres (mil millones de seres humanos viven en el planeta en una situación de pobreza).

Si ponemos a producir estos principios, los y las periodistas, en cuanto servidores sociales, no pueden ni deben eludir los graves desafíos que presenta la realidad. En este sentido, algunos procesos que deben ser favorecidos desde su especificidad son: frente a la precariedad de la vida humana por la que pasan las mayorías, deben fomentar la justicia social, la solidaridad con los más débiles, la honradez, la austeridad, el bien común y los derechos sociales; frente al predominio del individualismo, la pasividad y el olvido, deben cultivar una conciencia personal y colectiva situada, responsable e histórica; frente a una cultura narcisista que lleva al hombre y a la mujer de la noticia al vedetismo y el divismo periodístico - como si ellos fueran los protagonistas principales de la información o el debate-, se debe considerar su papel como impulsadores de la circulación de conocimientos sobre la realidad y de posibilitadores de espacios de información y expresión ciudadana.

\subsection{Las limitaciones}

El Código no aborda otros tipos de relaciones de la actividad periodística no menos importantes y urgentes, a saber, el periodista frente a la economía publicitaria, el periodista frente a la capacitación profesional y el periodista frente a la democratización de la palabra.

No cabe duda que hoy día asistimos a una creciente influencia de la economía publicitaria sobre qué y cómo informar. En la práctica, esto puede derivar en graves limitantes y distorsiones del quehacer informativo: la verdad y la objetividad en la información quedan subordinadas a la rentabilidad y el markenting (el sensacionalismo y el morbo tienen más fuerza que la verdad); las agendas informativas quedan condicionadas por los intereses empresariales (decir la verdad podría implicar el retiro de publicidad); se desfavorece el desarrollo de una conciencia colectiva crítica, en la medida en que al perceptor se le concibe como un mero consumidor de cosas, ideas e informaciones.

Por consiguiente, un Código de ética periodística no puede eludir la necesidad de regular sus relaciones con este poder real, que podría resultar, 
de hecho, siendo una amenaza contra la libertad de información. Ante la creciente influencia de la economía publicitaria sobre los contenidos informativos, la moral de la información nos recuerda que el afán de lucro no debe convertirse en el motor decisivo de esta actividad. Sobre el interés de los medios de ganar dinero y de tener la máxima influencia y difusión, la ética enfatiza la finalidad social de este derecho, esto es, se informa para formar opinión, para sensibilizar sobre los problemas más importantes y para crear consensos sociales en tomo a la consecución de un bien común histórico. Este tema, no es abordado ni de forma implícita, mucho menos explícita en el presente Código. Brilla por su ausencia.

En lo que se refiere a la profesión, si bien está mencionada como uno de los ejes básicos del Código, nada dice sobre la necesidad de una mayor y mejor capacitación profesional del gremio. Recordemos que para poder cumplir con la misión de captar objetivamente la realidad y saber comunicarla, no sólo basta con lo que se ha dado en llamar "espíritu periodístico", sino que es necesario saber el qué (comunicar) y el cómo. No basta con un periodismo éticamente bueno, tiene que ser, a su vez, bueno técnicamente hablando. $Y$ eso supone un mayor esfuerzo de investigación sobre los grandes problemas de la realidad, y una correcta apropiación de conocimientos teóricos y técnicos (incluyendo el uso de los medios digitales), que de forma continua lo capaciten para la información periodística. Garantizar un mejor nivel de formación profesional del periodismo hubiese sido otro de los contenidos principales del Código. Su omisión es otro grave vacío.

Por lo que toca a la democratización de la palabra, el Código en mención hace algunas referencias importantes, pero insuficientes. Postula - como ya hemos indicado - el derecho del público a conocer los hechos y las opiniones, la prioridad de los intereses colectivos, el fomento del diálogo abierto con los interlocutores, el derecho de respuesta, etc., pero aún quedan aspectos sustanciales relacionados con el tema sin tratar. Por ejemplo, construir agendas informativas basadas en las vivencias, problemas y expectativas de los sectores que no están representados en los medios masivos; ejercer nuevos modelos de comunicación (horizontales y participativos) que la lógica de la economía publicitaria desecha; cultivar en la conciencia colectiva la dimensión crítica del pensamiento, y fortalecer y ampliar los espacios de expresión de la sociedad civil.

Otro aspecto que podemos tipificar como limitación es la ausencia de la perspectiva de género en los contenidos del Código. Las mujeres han ido incursionando cada vez más y con buen tino en el ámbito periodístico; sin embargo, el Código ni siquiera supera el lenguaje sexista. Se sigue hablando de "el periodista", dando la impresión de que el Código fue sólo discutido y redactado por hombres. Se podría objetar que esta observación adolece de purismo feminista, pero no es así. Lo que ocurre es que seguimos infravalorando -quizás ahora de forma sutil- lo femenino. Rescatar lo femenino en todos los ámbitos de la vida social, incluyendo a los distintos códigos que norman jurídicamente la convivencia humana, atañe también a la ética que busca la conformación de estructuras nuevas, de relaciones diferentes, de un nuevo lenguaje que haga palpable lo femenino. Algo de esta limitación se expresa en el hecho de que en la junta directiva de APES sólo hay una mujer, en la comisión de ética no hay ninguna.

Así como se establecen responsabilidades frente a la niñez (población vulnerable), debieran haberse estipulado criterios para reflejar en las informaciones una imagen real y valorada de la mujer. En este plano no es suficiente la referencia a evitar discriminaciones por razones de sexo, raza, nacionalidad o creencia religiosa. La problemática real de inequidad entre lo femenino y lo masculino -que abarca todos los ámbitos de la convivencia y que fortalece los modelos androcéntricos- es razón suficiente para incorporar en un Código de ética periodística el enfoque de género, que comprenda tanto la visibilidad de la mujer periodista como de la mujer sujeto de diversos roles.

El Código no enfrenta de manera directa lo que constituye uno de los obstáculos más serios con los que se encuentran los y las periodistas, esto es, la censura y la manipulación de la noticia. Irónica y paradójicamente, en muchos casos, los más grandes enemigos del derecho a la información son los empresarios del periodismo, que manipulan la información de acuerdo con sus intereses políticos, ideológicos y económicos. Es cierto que el Código sostiene que los intereses de la colectividad deben preceder a cualquier responsabilidad frente a las empresas y poderes públicos o privados (art. 4); que la lealtad a la empresa de comunicación ha de mantenerse en cuanto no sea incom- 
patible con su conciencia profesional (art. 32). No obstante, los deberes éticos de la empresa periodística están expresados de forma muy tímida: "el periodista hará los máximos esfuerzos para que el medio en el que trabaja ejerza el derecho de respuesta (art. 33), el periodista se esforzará para que el medio proporcione condiciones económicas, sociales y laborales adecuadas para su desempeño profesional" (art. 34).

Este apocamiento del Código parece estar evadiendo uno de los "cables de alta tensión" con los que se enfrenta el ejercicio del derecho a la información. Nos referimos al poder manipulador que tienen los dueños de las empresas periodísticas, cuyo profesionalismo suele terminar ahí donde se ven afectados sus intereses. Este Código parece olvidar que, en no pocas ocasiones, son los dueños del medio o los directores oficiosos quienes no sólo censuran, sino también manipulan la noticia en casos tales como la presentación parcial de una verdad con el propósito de que el ciudadano no pueda aprehender la totalidad de los hechos; la información orientada a alimentar los sentimientos morbosos o la curiosidad malsana de los ciudadanos, convirtiendo la noticia en un conjunto de detalles que describen innecesariamente hechos en sí mismos inmorales, amorales o patológicos; la omisión de determinadas informaciones, cuyo conocimiento pondría en duda o al descubierto inconfesables intereses de los dueños de los medios de comunicación social; la mezcla de noticias y su interpretación ideológica, presentando ésta última como parte de los hechos expuestos; la manipulación del pasado, presentando como éxito lo que, a lo mejor, no es más que una crueldad; adoptar una actitud de marcada aunque aparente profesionalidad, cuando se están, de hecho, divulgando afirmaciones claramente parciales e interesadas; la generalización abusiva de hechos parciales con el fin de crear un Estado de opinión pública favorable o adversa respecto a una determinada realidad (Vidal, 1980).

Un Código de ética que pretenda responder a los problemas reales del periodismo, no puede ni debe rehuir el juicio moral sobre estas desviaciones, que son más habituales de lo que pensamos entre los empresarios de la noticia.

\section{Reflexión final}

Para recuperar la dimensión ética en el quehacer periodístico, es también importante tomar en cuenta tres aspectos que ha mencionado el Papa en su Mensaje para la XXXIIl Jornada Mundial de las
Comunicaciones Sociales (ver Mensaje, 1999). El lo plantea en términos de lo que la cultura de la Iglesia puede aportar a la cultura de los medios de comunicación y viceversa. Nosotros lo aplicamos al vínculo entre ética e información. Parafraseando lo expuesto por el Papa en su mensaje y a la luz del objeto de nuestro análisis, podemos decir que una ética de la información debe incluir la cultura del recuerdo, la cultura de la sabiduría y la cultura de la alegría.

Una cultura del recuerdo (de la memoria histórica) que pueda salvar a la cultura de la fugacidad de la noticia, del olvido que corroe la esperanza, propia de los medios de comunicación modernos. El derecho a la información no tiene que ver sólo con la facultad de los periodistas de recabar información en nombre de la sociedad; tampoco se limita al derecho de las personas a recibir noticias verdaderas o al derecho a la réplica. Tiene que ver también con el derecho a conocer y cultivar su memoria histórica en lo que tiene de pasado, de presente y de posibilidades futuras. Frente a la tendencia de la fugacidad y el olvido (que pueden terminar siendo formas de encubrimiento), la ética propondría la fuerza del recuerdo histórico en lo que tiene de tragedia y de esperanza, de luces y de sombras.

Una cultura de la sabiduría que pueda evitar que la cultura de la información, propia de los medios, se convierta en una acumulación de hechos sin sentido. Se afirma (Sobrino, 1998) que nunca ha habido tantas posibilidades para conocer la verdad, tantos centros de investigación y difusión del conocimiento $y$, sin embargo, en nuestro mundo existe una ignorancia escalofriante de la realidad fundamental de la humanidad. Se ofrecen tantas noticias que se diluye la realidad principal; se ofrecen tantas y tan diversas interpretaciones de un mismo hecho que éstas se balancean y anulan una a otra, y la realidad más honda permanece oculta.

Frente a lo que pareciera ser un momento donde podemos saberlo casi todo y saberlo instantáneamente, la cultura de la sabiduría exige lucidez crítica para conocer los intereses ocultos que se esconden tras la apariencia de información. Exigiría una actitud activa por parte de las y los interlocutores, que los conduzca a saber pensar, a pasar de la ignorancia al saber, de la mentira a la verdad. Que los conduzca a superar una visión de la realidad atomizada y sin contexto. Saber distinguir lo esencial de lo secundario, tener la capacidad de 
ver y poner las cosas en su debido lugar, tener la palabra certera y el comportamiento requerido. En una palabra, tener buen sentido y sana razón (sabiduría) debiera ser una aspiración fundamental de periodistas e interlocutores.

Una cultura de la alegria que pueda contribuir a que la cultura del entretenimiento, propia de los medios de comunicación, no se convierta en una fuga sin alma de la verdad y la responsabilidad. Frente al egocentrismo y la alienación que puede generar una diversión sin freno (perversión del gozo); la cultura de la alegría celebra la vida, la amistad, la intimidad de los próximos, el encuentro fraterno, la posibilidad de un futuro con justicia. De ahí que el entretenimiento consumista banaliza; la alegría con sentido del gozo, en cambio, nos humaniza.

Un periodismo con este talante sabrá cultivar la solidaridad compartida; la justicia como juicio crítico de la arbitrariedad y la impunidad; la austeridad como freno al lujo excluyente y despilfarrador; la justicia ecológica para frenar la producción sin límites y el lucrocentrismo; la "civilización de la pobreza", entendida como una sociedad justa, donde nadie quede excluido del acceso a los bienes básicos.

\section{San Salvador, octubre de 1999}

Carlos Ayala Ramirez

\section{Bibliografia}

Asociación de periodistas de El Salvador, Código de ética de la prensa de El Salvador, San Salvador, 1999.

Mensaje de su Santidad para la XXXIII Jornada Mundial de las comunicaciones sociales, enero, 1999.

Luis López Forero y Luis José González Alvarez, Ética, Comunicación y códigos del periodismo,

- Bogotá, 1993, pp. 73-143.

Proceso, 874-875, El Salvador, 1999.

Jon Sobrino, "El espiritu de la verdad", Carta a las Iglesias, 409 410, San Salvador, 1998.

Temas claves para el Plan de Nación, consulta especializada, San Salvador, 1999, pp. 204-205.

Marciano Vidal, Moral de actitudes. Moral social, T. 3, Salamanca, 1980, pp. 428-448.

John Virtue, "Problemas éticos en América Latina", Revista Chasqui, 61, marzo, 1998, pp. 13-17. 